\title{
A REALEZA E A SAÚDE PÚBLICA EM PORTUGAL (SÉCULOS XIV-XVI)
}

\section{LA REALEZA Y LA SALUD PÚBLICA EN PORTUGAL (SIGLOS XIV-XVI)}

\author{
ROYALTY AND PUBLIC HEALTH IN PORTUGAL (FROM THE $14^{\text {TH }}$ TO $16^{\text {TH }}$ \\ CENTURIES)
}

\section{LA MONARCHIE ET LA SANTÉ PUBLIQUE AU PORTUGAL DU XIV ème AU XVI ${ }^{\text {ème }}$ SIECLE}

DOI: $10.5533 / 1984-2503-20135102$

Mário Jorge da Motta Bastos ${ }^{1}$

\section{RESUMO}

As sociedades medievais e modernas sofreram a frequência de diversos cataclismos e epidemias. Dentre essas, coube à peste a triste primazia em ceifar um elevado número de vidas, agindo em vagas recorrentes, principalmente a partir de meados do século XIV. Depois da grande epidemia de Peste Negra de 1348, a doença instalou-se no Ocidente, abatendo-o em focos endêmicos segundo datas e regiões variadas até fins do século XVI. Ao longo deste período, Portugal vivenciou, com caráter geral ou local, pelo menos um surto epidêmico por década. Em suma, convívio cotidiano e inquietante com a morte. Se os especialistas de hoje se esforçam por discernir as suas motivações, o que se dirá das populações afligidas? Essas também os tinham, e eles não tardaram a expressar, não hipóteses, mas certezas que buscavam disseminar. Neste artigo, abordaremos as intervenções da realeza portuguesa visando à superação das recorrentes epidemias de peste, que, orientadas pelas concepções religiosa e médica da doença, sustentaram a

\footnotetext{
${ }^{1}$ Professor Associado I do Departamento de História da Universidade Federal Fluminense, pesquisador do Translatio Studii - Núcleo Dimensões do Medievo, e do Núcleo Interdisciplinar de Estudos e Pesquisas sobre Marx e o Marxismo, na sua seção dedicada às Sociedades Pré-Capitalistas (NIEP-Marx-PréK). Publicou, em 2009, pela Eduff, o livro intitulado O Poder nos Tempos da Peste (Portugal - sécs. XIVIXVI) e tem, no prelo, pela Edusp, a obra intitulada Assim na Terra como Céu... Paganismo, Cristianismo, Senhores e Camponeses na Alta Idade Média Ibérica (Séculos IV-VIII).

E-mail: velhomario@gmail.com.
} 
imagem do Rei Saneador e deram ensejo às primeiras iniciativas da constituição do campo da saúde pública em Portugal.

Palavras-chave: Idade Média, Portugal, Realeza, Peste, Saúde Pública.

\section{RESUMEN}

Las sociedades medievales y modernas han sufrido la frecuencia de diversos cataclismos y epidemias. Entre ellas, la peste ha sido la que más ha matado, actuando en momentos recurrentes, sobre todo a partir de mediados del siglo XIV. Después de la gran epidemia de peste negra de 1348, la enfermedad se instaló en el Occidente, abatiéndolo en focos endémicos según fechas y regiones variadas hasta fines del siglo XVI. A lo largo de este periodo, Portugal ha experimentado, con carácter general o local, por lo menos un surto epidémico por década. En suma, un convivio cotidiano e inquietante con la muerte. ¿Si los especialistas de la actualidad se esfuerzan en discernir sus motivaciones, qué decir de las poblaciones afligidas? Estas también tenían este problema y no tardaron a expresar, no hipótesis, sino certezas que buscaron diseminar. En este artículo, abordaremos las intervenciones de la realeza portuguesa visando a la superación de las recurrentes epidemias de peste, que, orientadas por las concepciones religiosa y médica de la enfermedad, han sustentado la imagen del Rey Saneador y han dado oportunidad a las primeras iniciativas de la constitución del campo de la salud pública en Portugal.

Palabras clave: Medioevo, Portugal, realeza, peste, salud pública.

\section{ABSTRACT}

Both modern and medieval societies have undergone frequent and varied cataclysms and epidemics. Of these, the plague was the first to claim a high number of victims, striking in various waves mainly in the second half of the fourteenth century. After the widespread epidemic of the Black Death in 1348, the disease took root in the West, occurring across endemic foci in different periods and regions up to the end of the sixteenth century. During this period, Portugal experienced at least one epidemic outbreak per decade on both a general and local scale, and daily life was tinged by the threat of death. If experts today still struggle to identify the underlying causes, what might be said of the populations affected? The latter also had their theories, and wasted no time in expressing not just hypotheses, but certainties they sought to disseminate. In this article we consider the 
interventions made by the Portuguese monarchy with the aim of overcoming the recurring waves of the plague, which, as guided by religious and medical understandings of the disease, sustained the image of the Curative King and gave rise to the first constitutional initiatives in the field of public health in Portugal.

Key words: Middle Ages, Portugal, royalty, the plague, public health.

\section{RÉSUMÉ}

Les sociétés médiévales et modernes endurèrent régulièrement divers cataclysmes et épidémies. Dans ce contexte, la peste a toujours tenu le haut du pavé, fauchant d'innombrables vies en vagues successives, principalement à partir de la seconde moitié du $\mathrm{XIV}^{\text {ème }}$ siècle. Après la grande épidémie de peste noire de 1348, la maladie flagella diverses régions de l'Occident de manière endémique jusqu'à la fin du XVI ème siècle. Tout au long de cette période, le Portugal subit, globalement ou localement, au moins une épidémie par décennie, ce qui constitue en somme une coexistence quotidienne et inquiétante avec la mort. Si les spécialistes d'aujourd'hui s'efforcent de discerner les contours de cette réalité, que dire des populations affligées ? Celles-ci ne tardèrent pas à exprimer, non pas des hypothèses, mais des certitudes qu'elles cherchèrent à disséminer. Dans le présent article, nous aborderons les interventions de la monarchie portugaise visant à éradiquer les épidémies récurrentes de peste. Ces interventions, orientées par les conceptions religieuses et médicales de la maladie, donnèrent au roi son surnom de $R e i$ Saneador (le roi assainisseur) et donnèrent lieu aux premières initiatives de constitution du champ de la santé publique au Portugal.

Mots-clés: Moyen-âge, Portugal, monarchie, peste, santé publique.

\section{Introdução}

Minha atividade profissional de historiador está primariamente vinculada à medievalística, recorte espaço-temporal ao qual me dedico há muitos anos. Essa revelação inicial me parece importante em razão de uma série de particularidades que marcam a configuração do campo da História Política medieval. Em primeiro lugar, não é despiciendo que a chamada História Política Tradicional, tomada como principal adversário a ser batido no contexto de formação dos Annales, contou, dentre os 
promotores daquela saraivada de críticas que se encontra nas obras polemistas dos fundadores da "escola", com o papel ativo no front de um grande medievalista, Marc Bloch, que concorreu para detratá-la - à história política tradicional - por seu caráter factual, linear, elitista, e por seu "curto fôlego". E não podemos nos esquecer que o mesmo Marc Bloch, alguns anos antes de "subir ao ringue e deflagrar o combate", publicara, em 1924, um clássico, obra exemplar da nova "história política" cuja proposta ficava enunciada. Deslocava-a da superfície agitada dos fatos para a profundidade serena das estruturas, do âmbito pouco denso da política para o mais substancioso do poder, flertando, ademais, com a noção ainda muito fluida de "inconsciente coletivo". Vinha à luz Os Reis Taumaturgos. ${ }^{2}$ A obra é conhecida de todos; o famoso estudo sobre a crença no poder de cura dos reis franceses e ingleses, taumaturgia régia especialmente manifesta na supressão das escrófulas, dolorosos inchaços dos gânglios cervicais que levavam multidões de doentes aos rituais públicos em busca do toque régio.

Porém, entre a crítica devastadora à "velha fórmula" e a afirmação de novas vias alternativas impôs-se, no que refere à história política medieval, um abismo de décadas registrado, por exemplo, num famoso artigo devido a Jacques Le Goff, datado de 1983, no qual se interrogava se a política seria ainda a ossatura da História! ${ }^{3}$ A pergunta parecia-lhe urgente àquela altura, e decorria da constatação de que os medievalistas haviam abandonado, quase que por completo, ${ }^{4}$ o campo do político desde o momento fundador dos Annales, passando a privilegiar a história social, a econômica e, logo, a das mentalidades, ângulos diversos de abordagem das sociedades favorecidos, em especial, pelos integrantes do "movimento" que já foi chamado de "a revolução francesa da historiografia". 5 Atestado o abandono, Le Goff passa, no referido artigo, a discorrer sobre a recuperação necessária do campo em questão, urgência que demandava a sua reformulação e renovação integrais, pautadas pelo abandono do "político" em prol do "poder", pelo apoio indispensável da Antropologia, pelo deslocamento das análises da esfera predominante do estado para a dos micropoderes, pela análise das relações entre poderes e saberes e, em especial, pela concentração do foco do analista nas expressões

\footnotetext{
${ }^{2}$ Bloch, Marc (1993). Os Reis Taumaturgos. O caráter sobrenatural do poder régio: França e Inglaterra, São Paulo: Companhia das Letras (original francês de 1924).

${ }^{3}$ Le Goff, Jacques (1983). "A política será ainda a ossatura da História". In O Maravilho e o quotidiano no Ocidente Medieval, Lisboa: Edições 70, p. 221-242.

${ }^{4}$ Exceção feita à obra de Kantorowicz, Ernst H. (1998). Os dois corpos do rei: um estudo sobre teologia política medieval, São Paulo: Companhia das Letras (original inglês de 1957).
} 
simbólicas do poder, nos rituais, nas mitologias políticas, enfim, nas mais diversas manifestações do fenômeno no âmbito preferencial das mentalidades ou, como se prefere designar nos dias que correm, das culturas políticas. ${ }^{6}$

Numa avaliação bem rápida, parece inegável que o artigo-manifesto frutificou, ampliando-se progressivamente desde então o conjunto de obras voltadas à análise dos níveis e âmbitos mais diversos das expressões do poder nas sociedades medievais. Índice do sucesso em questão, além de apoio considerável ao seu vigor, a obra clássica de Marc Bloch e, em seguida, a de Ernst Kantorowicz, mereceram reedições na França e na Inglaterra após permaneceram esgotadas por décadas, além das primeiras edições em língua espanhola e portuguesa (já na segunda edição no Brasil). A apresentação das reedições de Bloch coube ao mesmo Jacques Le Goff, que celebrou o caráter pioneiro da obra e, também, a enorme evolução ocorrida desde então, a seu juízo, nas perspectivas e instrumentos de análise dos fenômenos históricos manifestos no nível das mentalidades. Destaca, acima de tudo, que o racionalismo de Marc Bloch e o recurso à noção de "mentalidade pré-lógica", colhida em Lévy-Bruhl ${ }^{7}$ e aplicada aos "medievais", teriam privado o autor da capacidade de compreensão plena dos complexos mecanismos geradores do fenômeno da crença popular na taumaturgia régia.

De minha parte, devo-lhes dizer que não partilho o "entusiasmo pelo progresso" manifestado por Jacques Le Goff. Neste caso, creio que não se cumpriu o famoso adágio medieval: os anões subidos aos ombros do gigante sofreram de vertigem, enfermaram e reduziram em muito o alcance de suas visões; concentraram demais o foco de suas lentes, voltando-as aos detalhes e perdendo de vista a amplitude e a riqueza abrangente da paisagem! Nos limites desta apresentação, destaco apenas que, enquanto Marc Bloch considerou as articulações entre crenças e práticas, entre as representações e ações régias, entre as doutrinas e as intervenções efetivas que promoveram e alimentaram, mutuamente, a prática social da realeza na sua máxima amplitude, o campo de estudos padeceu nas últimas décadas de um retraimento progressivo e empobrecedor, articulado essencialmente por estudos restritos ao nível das representações, mais ou menos alheios a qualquer consideração das condições materiais de produção, circulação e consumo das

\footnotetext{
${ }^{5}$ Burke, Peter (1991). A Escola dos Annales: A Revolução Francesa da Historiografia (1929 - 1989), São Paulo: Ed. UNESP.

6 Ver Cardoso, Ciro Flamarion (2012), "História e poder: uma nova história política?". In Cardoso, Ciro Flamarion e Vainfas, Ronaldo (Orgs.). Novos Domínios da História, Rio de Janeiro: Elsevier, p. 37-54.

${ }^{7}$ Lévy-Bruhl, Lucien (1947). La mentalité primitive, Paris: Presses Universitaires de France (original francês de 1922).
} 
mesmas, operando-se uma desvinculação absoluta, nas análises, entre as expressões simbólicas, a prática e a reprodução material e institucional do poder em questão.

Assim, a história da realeza medieval talvez se preste à condição de exemplo por excelência do abismo profundo que opera a cisão entre o discurso e prática do poder, entre teoria e ação política, em que o segundo elemento do par representa um incômodo tremendo para o primeiro, mal-estar do qual o pesquisador prefere se esquivar. Será a prática a antítese do discurso, ou o discurso uma prática remetida ao mundo dos sonhos dos poderosos? Estarão ambas as expressões do poder fadadas a uma dicotomia insuperável como manifestações legíveis apenas em isolamento recíproco? Dedico as páginas seguintes à abordagem de algumas dessas questões, tendo por base o contexto ibérico de fins da Idade Média, com as iniciativas régias voltadas ao combate às epidemias de peste.

\section{A Incidência do Flagelo}

As sociedades medievais e modernas foram constantemente atingidas por diversos cataclismos e epidemias. Dentre estas, coube à peste a triste primazia em ceifar um elevado número de vidas, agindo em vagas recorrentes, principalmente a partir de meados do século XIV. Depois da grande epidemia de Peste Negra de 1348, a doença instalou-se no Ocidente, abatendo-o em focos endêmicos segundo datas e regiões variadas. Intrinsecamente nefasta, associada a este outro flagelo da humanidade que foi (é) a fome, produziram sangrias demográficas mais ou menos profundas, mas constantes, entre as populações dos séculos XIV ao XVI. E demarcaram nas cidades o palco privilegiado para a encenação de seu espetáculo de horrores.

O multifacetado espaço urbano surge-nos sobretudo caracterizado (em especial o dos grandes centros) pela riqueza, pela pujança do tráfego humano, da produção e circulação de idéias e mercadorias, espaço aberto por excelência, centros de atração. Mas foi-o também (o quadro não nos deve parecer muito estranho!) por uma sua espécie de contra-face, marcada pela errância e concentração de mendigos e vagabundos, feitos párias e lançados à marginalidade, de subempregados, "ganha-dinheiros", pobres 
esfomeados e subnutridos, apinhados nas vielas sujas e tortuosas dos bairros populares; locais da precariedade da vida, "onde se nasce e morre muito depressa". 8

Com efeito, as cidades reuniam condições propícias à deflagração freqüente de crises diversas. Um habitat concentrado, submetido a precárias condições de higiene, dependente do abastecimento externo, próximo e/ou longínquo, de alimentos básicos, faziam da população urbana alvo predileto dos repetidos contágios vários. $\mathrm{Na}$ extensa faixa costeira portuguesa os centros portuários, freqüentados por embarcações de diversas partes do mundo, constituíram-se em vias de ingresso para epidemias que por vezes atingiram todo o território nacional.

Instalada, o tempo da doença era o da suspensão do burburinho das ruas, praças, mercados, talvez este o principal nível da ruptura. Caos momentâneo, é certo, porém a visita era freqüente. Em Lisboa, ao longo dos séculos XVI e XVII, registrou-se "em média para cada três anos normais um de mortalidade extraordinária, distribuídos de forma irregular, embora manifestassem certa periodicidade." ${ }^{9}$ Desiguais em sua força destrutiva, a peste esteve sempre na origem das grandes mortandades: calcula-se que sessenta mil pessoas, numa população orçada em cento e vinte mil, tenham sucumbido na capital durante a peste grande de 1569. Ao longo dos séculos XIV, XV e XVI Portugal vivenciou, com caráter geral ou local, pelo menos um surto epidêmico por década. ${ }^{10} \mathrm{Em}$ suma, convívio cotidiano e inquietante com a morte. Urgia opor-se-lhe! Se os especialistas de hoje se esforçam por discernir as suas motivações, o que se dirá das populações afligidas? Estas também os tinham, e eles não tardaram a expressar, não hipóteses, mas certezas que buscavam disseminar.

A doença pertence à história "porque não é mais do que uma ideia, um certo abstrato numa complexa realidade empírica."11 Não há que duvidar de sua "materialidade", dolorosamente manifesta, no nosso caso específico, num bubão pestoso. No entanto, mais do que um fator biológico, a doença é um elemento de cultura. Ela é o que dela se diz ao longo do milenar contato do homem com os agentes patogênicos. $\mathrm{E} o$ que dela se diz não é unívoco, diacrônica e sincronicamente, constituindo-a em objeto e campo de conflito histórico entre supostas verdades mais ou menos divergentes,

\footnotetext{
${ }^{8}$ A frase é de Chaunu, Pierre, Apud Rodrigues, Teresa (1990). Crises de Mortalidade em Lisboa. Séculos XVI e XVII, Lisboa: Livros Horizonte, p.79.

${ }^{9}$ Ibidem, p.71.

${ }^{10}$ Segundo Meireles, A. C. Vieira de (1866). Memorias de Epidemologia Portugueza, Coimbra: Imprensa da Universidade.
} 
concorrentes. Quanto às epidemias de peste, explicá-las, circunscrevê-las, consistia antes do mais em forjar um quadro tranquilizador, conceber uma ordenação em meio ao caos, instituir a coerência lógica de um sentido do qual, ao cabo, apresentar-se-iam os remédios ou alternativas de superação.

Intervenção recorrente, portanto, de um poder desestruturador, a peste instaurava a desordem, as ações descontroladas. Suscitou, na extensão, reações ordenadoras, de preservação da ordem social. Num contexto de afirmação do poder régio, em Portugal, sob a dinastia de Avis, a realeza requisitou-se o poder ordenador, de intervenção social contra o flagelo. Dessa forma apropriada, a reação à doença manifesta-se como um nível particular das práticas intervencionistas do Estado, contribuindo para a compreensão da complexidade do processo mais global, posto que a ele se articula, da centralização política então em curso. Em Portugal, se não foi o Estado centralizador sob Avis que fundou o "campo" da saúde pública municipal, este se definiu e especializou-se sob sua ingerência, contribuindo, a esse nível, para afirmar a supremacia do Estado.

\section{O Rei Saneador}

A intervenção do poder régio sobre os concelhos, no que diz respeito ao estabelecimento das medidas de saúde pública, deu lugar a um "diálogo" constante entre as duas instâncias de poder ao longo do período. Nesse contato, se situações houve em que a urgência da ação demandou a iniciativa das autoridades locais ${ }^{12}$, estas freqüentemente consultavam previamente o soberano, propondo medidas e aguardando a sua deliberação. No sentido oposto, muitas vezes a realeza antecipava-se às consultas, determinando, em geral através de cartas régias emanadas da Chancelaria, a deliberação de medidas que, no entanto, só seriam aplicadas depois de sua aprovação. Casos houve em que o poder central, fixava os regimentos sem anuência ou consulta prévia às municipalidades.

Aquelas conjunturas nas quais a presença do flagelo se fazia mais incisiva foram, obviamente, as mais favoráveis ao incremento das determinações régias. Assim, apenas

\footnotetext{
${ }^{11}$ Segundo Le Goff, Jacques (Apres.) (s.d.). As Doenças têm história, Lisboa: Terramar, p.7.

${ }^{12}$ Segundo Tavares, Maria José Pimenta Ferro (1987). "A Política Municipal de Saúde Pública (séculos XIVXV)". In Revista de História Económica e Social, n. 19, jan./abr., p. 32; Dias, João José Alves (s.d.). A Comunicação entre o Poder Central e o Poder Local: a difusão de uma lei no século XVI, mimeo.
} 
nos quatro primeiros meses da epidemia que assolou Lisboa no biênio de 1520-21, compulsamos cinco cartas consecutivas pelas quais D. Manuel estipulou medidas diversas no intuito de erradicar o contágio. Na última, datada de 04 de julho de 1520 , respondeu negativamente à consulta da câmara sobre a possibilidade de celebrarem, com festas públicas e procissões, o declínio do contágio ${ }^{13}$. Contudo, não só a elevada freqüência da doença, quanto o pressuposto de que podia, e devia, ser evitada, originou prescrições que parecem transcender o momento de sua efetiva presença. Atestam-no as reiteradas determinações régias, e a pressão sobre as autoridades concelhias, no sentido da provisão da limpeza urbana, bem como da prevenção, tanto contra a "importação de peste estrangeiras", quanto contra a disseminação nacional de epidemias locais.

A despeito de certa imprecisão, é possível discernir-se a paulatina criação e/ou especialização de ofícios e instituições na área da saúde, com base em iniciativas régias. Vejamos o caso do Provedor-Mor da Saúde. A primeira referência à função surgiu-nos na fundação do Tribunal da Saúde de Lisboa por D. João III, em 1526. ${ }^{14}$ D. Manuel não Ihe fez menção aquando da reorganização por ele promovida nos serviços municipais da cidade, em 1509, restringindo-os a quatro "pelouros", entre os quais o da limpeza urbana. $^{15}$ Contudo, Eduardo Freire de Oliveira ${ }^{16}$ destaca que, dentre as atribuições primitivas do concelho lisbonense, e uma das mais importantes, constava a superintendência do serviço sanitário, incumbência que recaía sobre um dos vereadores através de sorteio anual. Empossado, intitulava-se Provedor-Mor da Saúde e sua ação, sujeita a posturas e regimentos sancionados pelo poder central, transpunha os limites da cidade e do termo. Competia-lhe, por resoluções régias, o provimento de todos os ofícios ligados à saúde, tanto nos portos do mar e ilhas adjacentes quanto no interior do continente. De certo, sabemo-lo atuante por alturas de 1571. Aos 07 de janeiro D. Sebastião, por alvará endereçado à vila de Autoguia e a várias outras do Reino, determinou que as autoridades locais cumprissem com diligência as disposições do Provedor-Mor da Saúde de Lisboa, que por ordem sua as fixava no intuito de proteger o Reino contra a epidemia que atingira Peniche. ${ }^{17}$

\footnotetext{
${ }^{13}$ As quatro primeiras cartas datam de 09 de abril, 19 de maio, 20 e 23 de junho de 1520, Apud Oliveira, Eduardo Freire de (1887). Elementos para a História do Município de Lisboa, Lisboa: Typographia Universal, Tomo I, p. 469-470.

${ }^{14}$ Apud Meireles, A. C. Vieira de (1866). Op. Cit. , p. 62- 64.

${ }^{15}$ Por carta régia de 01 de fevereiro de 1509, Apud Oliveira, Eduardo Freire de (1887). Op. Cit., p. 10.

${ }^{16}$ Ibidem, p. 452-453.

${ }^{17}$ Ibidem.
} 
Além da especificação de cargos que, municipais, mas submetidos às determinações régias impunham-se como vetores da política centralizadora, originaramse dela também instituições, como os hospitais para epidemiados, expressão sobretudo das medidas de isolamento, das ações voltadas para segregar, isolar o "mal". Nesse sentido, data de 1526, em Lisboa a fundação do Tribunal da Saúde, ${ }^{18}$ primeira manifestação do poder central, tímida e circunscrita, é certo, de exercer um controle sobre o obituário da população. Tratava-se, neste caso, de manter um registro das causa mortis diárias na cidade, visando identificar, na origem, as "mortes suspeitas" denunciadoras da possível eclosão de um surto epidêmico. Considerada a infestação freqüente da capital, D. João III determinou a instalação, na Igreja de S. Sebastião da Padaria (localizada no centro da cidade), de um grupo de oficiais responsáveis pela provisão da saúde pública. Manter-se-iam reunidos, diariamente, dois provedores, um escrivão, um meirinho e um físico, supervisionados pelo provedor-mor da saúde da cidade. Haveria em cada freguesia um Cabeça da Saúde, vinte e nove no total, cuja função residia em registrar os óbitos diários em sua circunscrição, a partir das certidões juradas expedidas pelos físicos, em que estes especificavam a causa da morte. Em não sendo "suspeita" (morte súbita, com dores e febres!) o "cabeça" liberaria o enterro dando "escrito pera o coueiro aver de fazer coua." ${ }^{19}$ Nas reuniões diárias, realizadas no tribunal, cabia-lhes, por fim, comunicar aos provedores o número de mortes registradas, entregando-lhes as certidões. Sabemos, neste caso, que sobre as rendas da cidade recaía o pagamento dos oficiais, à exceção dos cabeças da saúde, pagos pelo erário régio. Mas se o "diálogo" entre o Rei e os concelhos, a fixação das medidas, a criação dos cargos e instituições foram os veículos da política de centralização no campo da saúde pública, estes se orientaram pela, e afirmaram socialmente, a concepção régia da doença.

A produção de um discurso régio sobre a doença, veículo de sua expressão e, logo, da determinação de medidas e condutas que se impunham em oposição ao "mal", embasou-se na apropriação dos discursos religioso e médico, amalgamando-os, revestindo-os da sua autoridade. Contudo, e como suposto do próprio conceito, o poder central os reequaciona, oscila entre pólos, investe-os diferencialmente, considerando as

\footnotetext{
${ }^{18}$ Meireles, A. C. Vieira de (1866). Op. Cit., p. 62-64.

${ }^{19}$ Ibidem, p. 64.
} 
contradições de fundo que expressam. A apropriação instaura um novo discurso, absoluto, posto que submetido na prática à lógica do poder.

Logo na fundação da dinastia de Avis, a intervenção de Deus no curso da história materializada com uma "peste-castigo" realçou que, para além do apoio "popular", o divino era favorável à ascensão do Mestre de Avis, destacando a preservação da Aliança na base da instauração da nova casa dinástica. Segundo Fernão Lopes, sofria a cidade de Lisboa com a falta de mantimentos devido ao cerco imposto por D. João de Castela (em fins de maio de 1384), minando-se assim paulatinamente a sua capacidade de resistência. Desesperançosos de outro recurso, veio o divino, quando "prougue aaquell Senhor que he Primçipe das hostes, e Vemçedor das batalhas que nom ouvesse hi outra lide nem pelleja senom a Sua; e hordenou que o angio da morte estemdesse mais a sua maão e percudisse asperamente a multidom daquell poboo." 20

Imediatamente o fogo da peste ateou-se no arraial e, realçando o seu caráter punitivo, atingiu apenas os castelhanos, que morriam diariamente às centenas, não afligindo dos portugueses nem mesmo os prisioneiros deliberadamente colocados em contato com os doentes. Perseverante, o rei manteve o cerco, até que contaminada a rainha entendeu "que nom prazia a Deos de alli mais estar." ${ }^{21}$ Livre do cerco (no início de setembro), a tribulação imposta a cidade se traduz num elemento de propaganda e reforço da piedade geral, e do caráter messiânico da realeza nacional. No dia seguinte à partida do exército invasor, ordenou-se uma grande e devota procissão de graças, à qual acorreu, além de todo o povo, o bispo da cidade e o Mestre, todos descalços, partindo da Sé à Igreja da Santíssima Trindade. Ao cabo, pregou-Ihes Fr. Rodrigo de Cintra, franciscano mestre em Teologia, fazendo do futuro D. João I um rei bíblico, e de Lisboa uma Jerusalém cercada e afligida, mas salva afinal pelo apoio iniludível do Senhor ao seu povo eleito. Reforçados Nele, e certos do seu rei, posto que o Juízo divino vaticinou a injustiça da causa castelhana, alçaram todos "as mãaos ao çeeo dãdo muitas graças ao alto Deos que os assi desabafara do poder de seus emmiigos."22

Pouco mais de um ano volvido o episódio, o já então aclamado rei D. João I afirmava, por carta régia endereçada à Lisboa, sua função de defensor da ortodoxia religiosa, e na extensão da saúde da cidade que se alçava como cabeça do Reino.

\footnotetext{
${ }^{20}$ Segundo Lopes, Fernão (1991). Crónica de D. João I, Porto: Livraria Civilização, v. I, p. 310.

${ }^{21}$ Ibidem, p. 312.

22 Ibidem, p. 320.
} 
Através da missiva, determinou o expurgo dos erros de idolatria que a maculavam, e que na perspectiva régia originavam a "doença-castigo". Condenou em especial o pecado da blasfêmia, em função do qual "deos envya ao poboo fomes, e pestelençias e terramotos $[\ldots]^{23}$. Destaque-se que a decisão real confirmou o dispositivo camarário estabelecido aos 14 de agosto de 1385, buscando os homens bons do concelho, através dele, dada a eminência da guerra contra Castela (que teve lugar no mesmo dia, Aljubarrota), garantir o apoio da misericórdia divina, "a q solamente o Regno e a cidade [Lisboa] pode livrar."24 Sancionados pela "realeza cristianíssima", tais dispositivos viriam a integrar as Ordenações Manuelinas. ${ }^{25}$

Mas, se na referência acima a realeza de Avis, no seu contexto fundador, integra, globalmente, através de seu cronista, umas das perspectivas básicas da concepção cristã - a peste atinge e explicita o pecado, punindo o estrangeiro invasor - o segundo rei da dinastia daria ensejo a primeira matização dos discursos, "instaurando" a concepção régia, fadada a largo futuro. No seu Leal Conselheiro, ${ }^{26} \mathrm{D}$. Duarte dedica-se a abordar a licitude da fuga dos centros contaminados pela peste. A referência, de per si, pressupõe o peso da condenação moral da atitude pelo discurso cristão, contrária ao conselho primeiro, e velho de séculos, avançado pela medicina. A opinião régia era, desde logo, a de que fugir da epidemia era atitude não só lícita, como de obrigação, até para com Deus. À exceção dos que eram obrigados a permanecer, não fugir à peste era antes um ato pecaminoso, tentação à divindade e auto-entrega em suicídio.

Naturalização da doença? Atenuação do poder da cura divina? Não se trata de renegar o recurso ao sagrado, o reforço da fé e da piedade individual como pauta fundamental à preservação da ordem e da saúde, mas de ancorá-lo num suposto livre arbítrio, que retira força das referências médica e religiosa submetendo-as à deliberação monárquica. O discurso régio elabora-se num processo dialético no qual investe e desinveste as autoridades concorrentes, impondo a sua, reforçada pelo poder do Estado. A misericórdia divina mantém-se desejada, fundamental, e o resgate da sociedade pecadora é dever, e força, de um rei cristão.

\footnotetext{
${ }^{23}$ A carta régia data de 27 de agosto de 1385, Apud Oliveira, Eduardo Freire de (1887). Op. Cit., p. 20.

24 Ibidem.

${ }^{25}$ Costa, Mário Júlio de Almeida (Ed.) (1984). Ordenaçoens do Senhor Rey D. Manuel, Lisboa: Fundação Calouste Gulbenkian, L. V. tits. XXXIII - XXXIIII e XLV, cuja versão definitiva foi publicada em 1521, segundo Serrão, Joel (1980). Cronologia Geral da História de Portugal, Lisboa: Livros Horizonte, p. 96.

${ }^{26}$ Piel, Joseph M. (Ed.) (1942), Leal Conselheiro, Lisboa: Livraria Bertrand, cap. LIV, p. 224 - 230.
} 
O próprio D. Duarte aprovou ${ }^{27}$, dentre as medidas propícias ao livramento de Lisboa do contágio, em 1437, a realização de missas diárias em todas as igrejas da cidade, bem como uma procissão geral todas as sextas-feiras. D. Afonso $\mathrm{V}$, em fevereiro de 1453, convocou a cidade do Porto, através das autoridades concelhias, a realizar procissões e preces rogando a Deus que livrasse Ceuta do contágio que a assolava. ${ }^{28}$

A maior parte das missivas incluem medidas profiláticas aconselhadas pela física, fazendo-se depender a saúde pública da graça divina e das ações humanas combinadas. Ambas orientadas pelas determinações régias. Contudo, e pelo menos a partir do reinado de D. Manuel, ressaltando-se uma outra oposição de fundo entre os discursos, parecenos impor-se, sob a ótica do poder, a referência médica. Pretendendo o povo de Lisboa celebrar o arrefecimento do contágio que a assolou em 1520, com festas e procissões, estabeleceu o rei que estas fossem adiadas até que a cidade estivesse completamente livre da doença. ${ }^{29}$ D. João III, estando a capital novamente contaminada em 1523, proibiu, neste ano, a realização da procissão do Corpo de Deus. ${ }^{30} \mathrm{D}$. Sebastião, considerando finalmente salva a capital da Peste Grande, recomendou à câmara que realizasse então a procissão que esta havia-lhe proposto, agradecendo-se a Deus o milagre que a restituiu em saúde. Realizou-se aos 20 de abril de $1570,{ }^{31}$ sete dias após a sua recomendação. Ressaltando a ascendência régia sobre a piedade popular, as promessas votivas feitas pelas cidades dependiam de confirmação real. ${ }^{32}$ Assim, o mesmo monarca daria posteriormente a sua anuência à realização anual da procissão, conhecida como "da saúde". ${ }^{33}$

D. Duarte firmara o princípio, sem extrair dele todas as conseqüências. A concepção religiosa, respaldada na premissa isidoriana, secundarizava a intervenção médica, submetendo-a aos desígnios do Criador. A fuga, seu principal conselho, traduziao como pecado. Positiva, sem dúvida, cristianizada, indicava os lenitivos do corpo, que eram inferiores, porém, aos remédios da alma. No referencial cristão, o tempo da epidemia é o do castigo maior, o da justiça divina. E que se exercia por suas próprias

\footnotetext{
${ }^{27}$ Carta Régia de 11 de setembro de 1437, Apud Oliveira, Eduardo Freire de (1887). Op. Cit., p. 12.

${ }^{28}$ Carta régia de 9 de fevereiro de 1453, Apud Bastos, Artur de Magalhães (Ed.) (s.d.). Livro Antigo de Cartas e Provisões dos Senhores Reis D. Afonso V, D. João II e D. Manuel I do Arquivo Municipal do Pôrto, Porto: Publicação da Câmara Municipal do Pôrto, p. 5.

${ }^{29}$ lbidem, p. 469-470.

${ }^{30}$ Por cartas régias datadas, respectivamente, de 2.06.1523 e 13.04.1570, Apud lbidem, p.471 e 576.

31 Segundo lbidem, p. 578.

32 Segundo Ibidem, p. 458.

${ }^{33}$ Por carta régia de 19 de abril de 1572, Apud lbidem, p. 583.
} 
mãos. Interregno terreno, o Rei dos reis dominava o curso da história: o Deus encolerizado resumia em si a manifestação exclusiva do poder, exercendo-se e se afirmando sobre a comunidade. Face a Ele, a única reação humana efetiva era a autoentrega, a passividade e a aceitação, conduta indispensável para o resgate, orientada pelo clero. Haveria lei humana a opor-se-lhe?

O discurso religioso, em sua matriz clerical, desautorizava a realeza. Quem era o rei, senão mais um, ou o principal pecador? Não era ele, com toda a corte, o primeiro seguidor de Hipócrates? Não atraía, sobre o povo, a doença por seus pecados? A reação régia contra tais premissas, expressa já no Leal Conselheiro, significou o resgate da sua própria possibilidade de intervenção, a reafirmação de sua autoridade e poder. Não sobre o sagrado, que lhe transcendia, e era ainda um de seus principais fundamentos, mas sobre o exclusivo da ordus clerical na sua interpretação terrena. Oposição entre os discursos, repetimo-lo, mas que de fato se revela e exacerba no seu processo de apropriação, posto que instaura um absoluto, cuja afirmação social demanda a submissão das autoridades concorrentes.

Em se tratando do discurso médico, a realeza muito mais investiu-lhe do que lhe atenuou a autoridade de base. Em Portugal, o seu locus de produção estava sob a dependência régia, que ainda mais "acentuou-se à medida que se acentuava a centralização política." $^{34}$ Contudo, mais do que a subordinação da Universidade de Coimbra ao rei destaque-se, no contexto dessa análise, o investimento régio na normatização do exercício da medicina. D. João I, por lei geral de 28 de junho de $1392,{ }^{35}$ determinou a obrigatoriedade do licenciamento, através de exame pelo "Fysico d'El-Rey", a todos aqueles que no reino se dedicassem a "arte da física", fixando aos transgressores a pena de prisão e perda dos bens. Por carta régia enviada à Lisboa em 1385, condenava como prática idólatra a feitura de "remedio outro alguu para saude dalguu home ou animallia, qual nõ cõsselhe a arte da fisica [...]". ${ }^{36} \mathrm{~A}$ mesma referência colhe-se,

\footnotetext{
${ }^{34}$ Segundo Saraiva, António José (1988). O crepúsculo da ldade Média em Portugal, Lisboa: Gradiva, p. 129.

${ }^{35}$ Apud Almeida, Antonio de (1813). "Colleção da Maior Parte dos Estatutos, Leis, Alvarás, Decretos, e Ordens Relativas a Medicina e Cirurgia... em Portugal". In Jornal de Coimbra, v. III, n. XIV, p. 205-206.

${ }^{36}$ Veja-se a nota 18.
} 
de um lado, nas Ordenações Manuelinas ${ }^{37}$, e de outro no De Correctione Rusticorum, de S. Martinho de Braga, datado do século VI. ${ }^{38}$

Normatizar a medicina consistiu, portanto, em fixar o seu campo legal, o da tradição antiga cristianizada, e erudita, fazendo derrapar para o âmbito proscrito da feitiçaria as práticas desviantes, não canonizadas. A esta lei primeira de D. João seguiuse uma vasta legislação posterior. D. Afonso V, por regimento de $1448,{ }^{39}$ estabeleceu a obrigatoriedade do exame para os cirurgiões, prestados perante o cirurgião-mor da Corte. D. João II concedeu, em 1481, poder de polícia ao Cirurgião-Mor, permitindo-o fazer-se acompanhar de três homens armados para "prenderem os que uzassem [do ofício] sem Carta de Licença [...]" $]^{40}$. Guardião da medicina legal, esta orientaria os principais níveis de intervenção da realeza contra a doença.

Em primeiro lugar, embasado no binômio galênico "podridão/peste", o poder régio deu ensejo a uma efetiva política de higienização urbana, pública e privada. As primeiras posturas camarárias, conhecidas em Portugal, datam de fins do século XIV. Uma série delas, relativas à Évora circunscreve-se aos anos de 1375 a 1395. Do conjunto dos dispositivos, apenas uma pequena parte diz respeito à limpeza urbana, orientando a remoção de lixos, estercos, águas acumuladas e dejetos dos mesteres, proibindo o trânsito de porcos pelas áreas públicas, o despejo de esterco em covas de pão abandonadas, etc. Contudo, como premissa orientadora de tais deliberações não se explicita a vinculação entre as condições de higiene e a doença, mas a preocupação das autoridades com o aspecto da cidade. Proibia-se o acúmulo da sujeira porque "a cidade e ruas pareciam mal". ${ }^{41}$

Já no Regimento da Cidade de Évora, fixado por D. João I em 1392, se não se faz alusão direta à peste, e se não se descarta o "parecer mal", impõe-se a relação direta entre a doença e as condições de higiene, a necessária provisão desta para debelar aquela, porque "das çujidades e estercos e cousas podres e nojosas e fumos que se delas fasem nos logares recrescem muytos danos e dores aos corpos e ainda parece mal os lugares onde se tal cousa consente [...]". ${ }^{42}$

\footnotetext{
${ }^{37}$ Costa, Mário Júlio de Almeida (Ed.) (1984). Op. Cit., L. V, tit. XXXIII.

${ }^{38}$ Veja-se Chaves, Luis (1957). "Costumes e Tradições vigentes no século VI e na actualidade". In Bracara Augusta, v. VIII, p. 243-278.

${ }^{39}$ Apud Almeida, Antonio de (1813). Op. Cit., v. II, n. VII, p. 58.

${ }^{40}$ Apud Ibidem, v. II, n. VIII, p. 137.

${ }^{41}$ Segundo Roque, Mário da Costa (1979). Op. Cit., p. 202.

42 Apud Ibidem.
} 
Daí em diante, a tônica seria a pressão, constante e crescente, do poder central sobre os municípios no sentido da adoção, generalização e aprimoramento das medidas de higiene urbana, sob o pressuposto de que eram o meio essencial da erradicação das epidemias. As disposições do regimento de D. João I, além de tratarem mais detalhadamente das esterqueiras, animais mortos, águas potáveis, etc., foram estabelecidas em 1420 na vila de Arraiolos, não sem antes se disseminarem para o Porto (1394) e Lisboa (1410). ${ }^{43}$ Insertas nas Ordenações Afonsinas, ${ }^{44}$ ganhariam estatuto de lei geral. Sob D. João II, a errância endêmica da peste, sobretudo em Lisboa, ao longo de quase todo o seu reinado (1481-1495), propiciou ao poder régio conjuntura favorável à efetivação de sua ascendência sobre este ramo da administração municipal.

Em janeiro de 1482 determinou que a câmara nomeasse "huu çidadão que tenha carreguo de olhar pela çidade que este limpa", e que ainda promovesse o encanamento articulado da capital, ligando as casa às ruas menores, e estas com as ruas principais, para que pudessem "deytar suas agoas çujas e vir a elles." ${ }^{45}$ Dois anos passados, nova carta régia $^{46}$, além de estabelecer a origem divina da epidemia que atingia a cidade, discorreu sobre os seus determinantes naturais: a falta de higiene pública decorrente das práticas do "entornar dos camareiros", o acúmulo clandestino de "monturos e esterqueiras" e o "entupimento dos canos", exigindo das autoridades medidas de reparação imediata. ${ }^{47}$ No ano seguinte, já o referimos, fixou a sua ascendência direta na determinação das posturas de limpeza da capital. Em janeiro de $1486,{ }^{48}$ por fim, condenando a falta de zelo no tratamento do tema, impôs à cidade um regimento de limpeza urbana. Ordenou, em primeiro lugar, a nomeação de um cidadão, com poder de polícia, que acompanhado por um escrivão zelaria pela higiene, impondo penas pecuniárias aos transgressores, e obrigando-os a reparar o delito. Determinou ainda que em cada freguesia houvesse homens a fazer a limpeza, com pagamento custeado pelas respectivas casas. Reiterou, por fim, a ordenação da construção da rede de esgotos da cidade, custeada em parceria pelas rendas públicas e os vizinhos.

\footnotetext{
43 Ibidem.

44 Costa, Mário Júlio de Almeida (Ed.) (1984). Ordenações Afonsinas, Lisboa: Fundação Calouste Gulbenkian, L. I., Tit. XXVIII II, p. 235-252.

${ }_{45}$ Apud Roque, Mário da Costa (1979). Op. Cit., p. 205.

${ }^{46}$ Apud Oliveira, Eduardo Freire de (1887). Op. Cit., p. 285.

${ }^{4}$ Segundo Roque, Mário da Costa (1979). Op. Cit., p. 206, D. João II fixou com esta lei os três principais problemas de higiene das cidades medievais.

${ }^{48}$ Por carta régia, Apud Oliveira, Eduardo Freire de (1887). Op. Cit., p. 463.
} 
Sob o "rei venturoso" não haveria de se arrefecer o ímpeto centralizador, e normatizador, consubstanciado nas posturas de higiene pública, particularmente dirigidas a Lisboa, "capital da Europa" e do império em formação. Por carta régia de 1506 determina o envolvimento coletivo dos cidadãos nos trabalhos de limpeza da cidade, a despeito de sua condição social. Problema novo colocado à saúde pública levou-o a determinar, em 1515, que a câmara ordenasse a prisão de escravos responsáveis por sujar a cidade. Em novembro do mesmo ano, considerando que os escravos mortos lançados aos monturos representavam perigo para a saúde da cidade, determinou à câmara que abrisse "huu poço, o mais fumdo que podese ser, no llugar que fose mais comvinhavell e de menos imcomvyniente, no quall se llãçasem os ditos escrauos [...]." O processo de ingerência do poder central neste campo da limpeza e saúde parece-nos ter, por sinal, chegado ao termo durante o governo de D. Manuel. Por carta régia de 30 de julho de $1510,{ }^{49}$ ordenava aos vereadores lisboetas, que the pediram licença de suas funções, que se mantivessem nos cargos, em função inclusive da epidemia que atingia então a cidade. Segundo Eduardo Freire de Oliveira a iniciativa do pedido fora feita em represália à ação régia, que havia privado a câmara da superintendência de alguns setores da administração, dentre eles o regimento da limpeza. ${ }^{50}$

Mas as medidas de caráter preventivo não se limitaram à normatização das práticas de higiene pública. A peste gerou, e o discurso médico o expressou amplamente, sobretudo suspeição. A certeza do perigoso contágio, veiculado pelo ar corrompido, ensejou posturas de isolamento, reclusão e confinamento através das quais o Estado manifestou, e afirmou, o seu poder sobre os cidadãos. Abordemo-las, em suas principais vertentes. A fuga foi a sua primeira expressão, já o dissemos, valendo-se dela amplamente a corte portuguesa. Muitos dos seus deslocamentos pelo reino no período tiveram lugar com a peste nos seus calcanhares. Em setembro de $1495,{ }^{51}$ a rainha D. Leonor comunicou-se com a câmara de Lisboa, pedindo informações sobre o estado de saúde da cidade, desejosa que estava de para ela retornar. Contudo, considerado o princípio firmado por D. Duarte, o abandono por parte das autoridades locais dependia de liberação régia. ${ }^{52}$

\footnotetext{
${ }^{49}$ Por cartas régias datadas, respectivamente, de 8.08.1506, 22.08.1515, 13.11.1515, 30.07.1510, Apud lbidem, p.402, 446, 509 e 411.

50 lbidem.

${ }^{51}$ Por carta régia datada de 15 de setembro de 1495, Apud Ibidem, p. 369.

${ }^{52}$ Segundo Tavares, Maria José Pimenta Ferro (1987). Op. Cit., p. 20.
} 
Quanto ao isolamento nas endemias, as primeiras referências em Portugal datam do século XV. D. Duarte, no Leal Conselheiro, indicava às autoridades municipais a adoção de três medidas básicas, visando a impedir a disseminação local do contágio: em primeiro lugar, deviam expulsar das cidades os doentes, para que se curassem ou morressem fora do centro de habitação; quanto aos mortos, fossem enterrados em cemitérios extra-muros e, por fim, que suas casas fossem encerradas por quinze ou vinte dias. ${ }^{53}$ Medidas, ainda uma vez, fadadas a largo futuro, e aprimoramento. No mesmo intuito, mas em sentido contrário, coibia-se o livre trânsito de pessoas oriundas de centros contaminados, o que pressupõe um sistema minimamente articulado de comunicação entre as regiões. A ordenação mais antiga nesse sentido, conhecida em Portugal, data do reinado de $\mathrm{D}$. Afonso $\mathrm{V}$. O ainda príncipe $\mathrm{D}$. João ordenou à vila de Beja a instalação de quatro postos de fiscalização nas suas portas de entrada, limitando o ingresso apenas aos viajantes que jurassem ter deixado as áreas contaminadas há, no mínimo, trinta dias. ${ }^{54}$ Em outubro de 1486, o então rei D. João II admoestou o concelho de Lisboa por ter permitido que ingressassem na cidade pessoas oriundas de Alhandra, onde então grassava a peste. ${ }^{55}$ Sob D. João III, a medida assume foros de crime de "lesa majestade": determinou, em julho de 1531, que qualquer pessoa que viesse a Évora, onde estava a corte, oriunda de Lisboa ou de regiões impedidas, fosse sumariamente executada. $^{56}$

A partir de D. João II, o isolamento dos doentes tendeu a se circunscrever num local fixo, fechado e externo ao centro urbano. Em 1480 ordenou à cidade de Évora o estabelecimento do primeiro hospital especificamente destinado ao encerramento de epidemiados, que seriam assistidos por um físico, pago pelo concelho. ${ }^{57} \mathrm{Em} \mathrm{1485}$, despachou a liberação de uma quinta nos arredores de Lisboa para o mesmo fim. ${ }^{58} \mathrm{D}$. Manuel, num contexto em que a realeza assumia o campo da caridade pública, projetou para Lisboa o primeiro hospital permanente para pestosos, que seria construído em local isolado para "menos se conversarem os doentes com a cidade." ${ }^{59}$ D. João III, em carta

\footnotetext{
53 Piel, Joseph M. (Ed.) (1942). Op. Cit., cap. LIV, p. 226.

${ }^{54}$ Segundo Tavares, Maria José Pimenta Ferro (1987). Op. Cit., p. 20.

55 lbidem, p. 21.

${ }^{56}$ Por carta régia de 03 de julho de 1531, Apud Oliveira, Eduardo Freire de (1887), Op. Cit., p. 455.

57 Segundo Tavares, Maria José Pimenta Ferro (1987). Op. Cit., p. 24.

58 Ibidem.

59 Segundo Roque, Mário da Costa (1979). Op. Cit., p. 186.
} 
resposta enviada à câmara de Coimbra, datada de 1 de setembro de $1525,{ }^{60}$ determinou a edificação urgente de um hospital, ao qual seriam recolhidos os pobres contaminados, sob os cuidados de um físico, um cirurgião e um barbeiro.

O caráter de segregação destas instituições revela-se da condição social dos internados, e das precárias condições de suas instalações: num hospital improvisado no Porto, em 1486, existiam apenas duas camas, ocupadas por seis a oito doentes que, rapidamente falecidos, davam lugar a outros tantos. ${ }^{61}$ Segundo Eduardo Freire de Oliveira $^{62}$, quando não se instalavam os hospitais, o Provedor-Mor da Saúde determinava o "entaipamento" dos pobres ("escrauos, e omees de soldada e obreiros dos macanicos") em bairros e ruas apartadas, enquanto a "gente grossa" permanecia em suas casas, sinalizadas pelos agentes da saúde.

A defesa contra pestes estrangeiras suscitou, no período, as primeiras medidas de polícia sanitária dos portos. D. João II esboçou, em 1492, o primeiro regimento para o porto de Belém, em Lisboa. Determinou o balizamento de sua entrada, que serviria de marco obrigatório para a paragem de barcos oriundos de regiões contaminadas. Recolher-se-ia a população num alpendre isolado, sob quarentena, depositando-se as mercadorias num pontão, ao sol, para desinfestação. A demora na execução da obra levou o monarca a repreender o conselho, em 1494. Contudo, durante as epidemias de 1492-1494, ${ }^{63}$ o concelho de Lisboa proibiu, por ordem régia, a atracação no porto de embarcações originárias da Alemanha e da França, e expulsou do Tejo naus fundeadas provenientes de Sevilha e da Andaluzia. ${ }^{64}$ Outro alerta preventivo foi expedido pela realeza aos portos costeiros em função da epidemia que, entre 1503 e 1504, assolou a Galícia. A vereação do Porto, a partir da ordem régia, proibiu a entrada de barcos oriundos daquela região, ordenando ainda aos pescadores galegos que se afastassem de seu porto. ${ }^{65}$

Na extensão, sob D. João III, impôs-se afinal a polícia do porto, com a criação da Casa da Saúde (ou do Despacho) de Belém, em 1526. Sediada na entrada do Tejo, serviam-Ihe um provedor, um escrivão, um meirinho e dois guardas. Fixou-a como parada obrigatória para as embarcações que adentravam o rio. Estas fundeavam junto a Casa,

\footnotetext{
${ }^{60}$ Apud lbidem, p.33.

61 Segundo Roque, Mário da Costa (1979). Op. Cit., p. 33.

62 Oliveira, Eduardo Freire de (1887). Op. Cit., p. 453.

${ }^{63}$ Por cartas régias datadas, respectivamente, de 5.09.1492 e 2.04.1494, Apud Ibidem, p. 363 e 369.

64 Segundo Tavares, Maria José Pimenta Ferro (1987). Op. Cit., p. 22.

65 Ibidem, p. 23.
} 
vindo o mestre mareante informar ao provedor, sob juramento, se era originário de porto "impedido", ou se passara por algum contaminado. $\mathrm{Na}$ seqüência, as mesmas informações eram tomadas a dois tripulantes, lavrando-se o auto pelo escrivão. Considerada insuspeita, permitia-se o acesso à cidade. No entanto, definida a sua proveniência de regiões contaminadas, determinava-se a evacuação da nau, posta sob vigilância dos guardas, transferindo-se a carga e os tripulantes para o Lazareto da Trafaria (na margem oposta do Tejo), submetendo-os a quarentena. ${ }^{66}$

\section{Considerações Finais}

Pelo exposto verificamos que, das primeiras medidas oriundas do poder central voltadas à superação da doença, expressas por D. João I, os séculos XIV ao XVI foram palco de sua especialização e complexificação, ampliando-se as frentes de combate a par da intensificação da ascendência do Estado sobre o campo da saúde pública.

Sob D. João III, a cidade de Lisboa, foco central da intervenção régia que, como a doença, se disseminava pelo reino, recebeu o seu primeiro regimento de saúde, redigido pelo "doutor" Pero Vaz por ordem do soberano, em 1526. Dos seus artigos, destaca-se o projeto de intervenção máxima de um poder que se pretende absoluto - a vigilância do indivíduo - impondo-se sobre a "célula" básica do corpo social. No item terceiro, fixa penas pecuniárias, de açoite e degredo "aquelle que não declarar o doente que tiver em casa de qualquer doença que seja dentro em duas horas da hora em que adoecer (...)". 67 Se a reiteração freqüente das determinações régias contra a doença ressaltam a oposição, mesmo que por inércia, à ação interventora do Estado, as penalidades por ele impostas destacam o elemento crucial, favorecedor da supremacia do seu discurso: a ideologia por ele veiculada reforça-se no poder que ele detém e exerce. Mas, em 1580, a mão interventora de Deus se fez novamente presente no curso da história, agora a apoiar ideologicamente o "novo poder" que se impunha: atingindo os portugueses com uma

\footnotetext{
${ }^{66}$ Segundo Roque, Mário da Costa (1979). Op. Cit., p. 190.

${ }^{67}$ Apud Meirelles. Op. Cit., p. 65.
} 
peste-castigo expressou, segundo um embaixador castelhano em Lisboa, ${ }^{68} 0$ apoio divino à causa de Filipe de Espanha. Deus, afinal, foi recurso primeiro, e último!

Por fim, como destacou Nieto Soria, "refletir sobre a monarquia supõe articular a referência a uma ética, a uma teoria e a uma prática do poder capazes de manter a lealdade dos súditos [...] e de guiar a própria realeza en sua ação de governo." ${ }^{9}$ Assim, mais do que consistirem em expressões díspares ou desconectadas, os veículos que acabo de referir articulam-se intimamente nas manifestações do poder régio, em que pesem as possíveis defasagens ou desníveis que os caracterizem neste mesmo processo de articulação. No Portugal do contexto a que nos referimos, a teoria política régia embasou a ação da realeza e sorveu da mesma, dialeticamente, argumentos favoráveis à sua reprodução. Pautada numa vigorosa metáfora organicista da sociedade apropriada, já desde os primeiros séculos medievais, à Igreja, os tratadistas configuraram a realeza como cabeça de um organismo vivo cujo equilíbrio e perfeita harmonia identificava-se à saúde, cabendo ao rei à função de físico, de um médico zeloso a quem competia administrar as mezinhas e evitar a doença, o contágio e a perdição do corpo social. Função saneadora régia, portanto, embasamento ideológico de uma prática intervencionista que se efetivava. Prática informada em imagens, imagens que consubstanciam práticas, ambas se conjugam para sublimar a dominação, expressandoa como necessária e indispensável à preservação da integridade de uma ordem social maculada pela mazela da desigualdade e dos conflitos sociais.

\section{Referências}

Almeida, Antonio de (1813). "Colleção da Maior Parte dos Estatutos, Leis, Alvarás, Decretos, e Ordens Relativas a Medicina e Cirurgia... em Portugal". In Jornal de Coimbra, v. III, n. XIV, p. 200-245.

Bastos, Artur de Magalhães (Ed.) (s.d.). Livro Antigo de Cartas e Provisões dos Senhores Reis D. Afonso V, D. João II e D. Manuel I do Arquivo Municipal do Pôrto, Porto: Publicação da Câmara Municipal do Pôrto.

\footnotetext{
${ }^{68}$ Segundo Silva, Luis Augusto Rebelo da (1862). História de Portugal nos séculos XVI e XVII, Lisboa, Imprensa Nacional, Tomo I, p. 434-435.

${ }^{69}$ Nieto Soria, José Manuel (1988). Fundamentos Ideológicos del Poder Real em Castilla (siglos XIII-XVI), Madrid: Eudema, p. 36.
} 
Bloch, Marc (1993). Os Reis Taumaturgos. O caráter sobrenatural do poder régio: França e Inglaterra, São Paulo: Companhia das Letras (original francês de 1924).

Burke, Peter (1991). A Escola dos Annales: A Revolução Francesa da Historiografia (1929 - 1989), São Paulo: Ed.UNESP.

Cardoso, Ciro Flamarion (2012), "História e poder: uma nova história política?". In Cardoso, Ciro Flamarion e Vainfas, Ronaldo (Org.) (2012). Novos Domínios da História, Rio de Janeiro: Elsevier, p. 37-54.

Chaves, Luis (1957). "Costumes e Tradições vigentes no século VI e na actualidade". In Bracara Augusta, v. VIII, p. 243-278.

Costa, Mário Júlio de Almeida (Ed.) (1984). Ordenações Afonsinas, Lisboa: Fundação Calouste Gulbenkian.

\section{Gulbenkian.}

Ordenaçoens do Senhor Rey D. Manuel, Lisboa: Fundação Calouste

Dias, João José Alves Dias (s.d.). A Comunicação entre o Poder Central e o Poder Local: a difusão de uma lei no século XVI, mimeo.

Kantorowicz, Ernst H. (1998). Os dois corpos do rei: um estudo sobre teologia política medieval, São Paulo: Companhia das Letras (original inglês de 1957).

Le Goff, Jacques (1983). "A política será ainda a ossatura da História”. In O Maravilho e o quotidiano no Ocidente Medieval, Lisboa: Edições 70, p. 221-242.

(s.d.). As Doenças têm história, Lisboa: Terramar.

Lévy-Bruhl, Lucien (1947). La mentalité primitive, Paris: Presses Universitaires de France (original francês de 1922).

Lopes, Fernão (1991). Crónica de D. João I, Porto: Livraria Civilização, v. I.

Meireles, A. C. Vieira de (1866). Memorias de Epidemologia Portugueza, Coimbra: Imprensa da Universidade.

Nieto Soria, José Manuel (1988). Fundamentos Ideológicos del Poder Real em Castilla (siglos XIII-XVI), Madrid: Eudema.

Oliveira, Eduardo Freire de (1887). Elementos para a História do Município de Lisboa, Lisboa: Typographia Universal, Tomo I.

Piel, Joseph M. (Ed.) (1942), Leal Conselheiro, Lisboa: Livraria Bertrand.

Rodrigues, Teresa (1990). Crises de Mortalidade em Lisboa. Séculos XVI e XVII, Lisboa: Livros Horizonte. 
Roque, Mário da Costa (1979). As Pestes Medievais Européias e o "Regimento Proueytoso contra ha Pestenença", Paris: Fundação Calouste Gulbenkian.

Saraiva, António José (1988). O crepúsculo da ldade Média em Portugal, Lisboa: Gradiva.

Serrão, Joel (1980). Cronologia Geral da História de Portugal, Lisboa: Livros Horizonte.

Silva, Luis Augusto Rebelo da (1862). História de Portugal nos séculos XVI e XVII, Lisboa, Imprensa Nacional, Tomo I.

Tavares, Maria José Pimenta Ferro (1987). "A Política Municipal de Saúde Pública (séculos XIV-XV)". In Revista de História Económica e Social, n. 19, jan./abr., p. 11-39.

Recebido para publicação em outubro de 2012.

Aprovado para publicação em dezembro de 2012. 